\title{
Food Safety Hazards Associated With Aquaculture Production Of Clarias Spp In Stagnant Water Bodies In The Niger Delta Area.
}

\author{
IBIM A. T.* \\ Department of Animal Science and Fisheries, Faculty of Agriculture, University of Port Harcourt, Choba, \\ Rivers State, Nigeria.
}

\begin{abstract}
Aquaculture production of Clarias species in the Niger Delta Area has become very popular in recent times. This is because the area is endowed with many inland water bodies that are pondable. The farming of Clarias species in the numerous stagnant inland waters poses potential food safety hazards.

This paper reviews the major food safety hazards associated with aquaculture production of Clarias species in stagnant ponds/water in the Niger Delta Area and proffers management and control strategies.

Aquaculture stakeholders are expected to ensure compliance of fish producers in order to ensure healthy food production.
\end{abstract}

Keywords: Aquaculture production, Clarias species, food safety hazards, Niger Delta Area.

\section{Introduction}

Aquaculture practices in the Niger Delta Area have increased dramatically, as seen in other parts of the country. This is as a result of the need for cheap but rich source of protein, high cost of beef as a source of protein, population explosion and subsequently, the inability of capture fisheries to meet the demand for fish and its products.

The increased need to culture Clarias in the Niger Delta Area is supported by the availability of numerous inland water bodies, flood plains, pondable land mass, with the ability to retain water for long periods and heavy and prolonged rains witnessed in this area.

The Clarias species also known as "Catfish" are indigenous species that are widely distributed in the Niger Delta Area. Their hardiness, efficient growth rates, high stocking density in culture systems, and especially, the possession of air-breathing organs, among other attributes have made them attractive to fish farmers. Also their popularity, palatability, large market sizes, sales as "live fish", less spiny flesh, among others have endeared Clarias species to consumers of fish products.

However, the culture of these species in this part of the world is mainly by subsistence/rural aquaculture undertaken in stagnant ponds, flood plains and other inland water bodies. Fish products produced in such systems are associated with potential food safety hazards. Ponds in the Niger Delta Area (being a heavily industrialized area) are likely to receive chemical effluents or seepage from the soil.

There is scarcity of information on the food safety hazards associated with the culture of Clarias species in the Niger Delta Area or elsewhere. Most literature deals predominantly with food safety issues of marine fish caught and produced in developed countries (Ahmed 1991a[1]; Ahmed 1991b[2]; Edwards 1999[3]). However, hazards and risks that may adversely affect the health of people are inherent in all human activities. Aquaculture is no exception to this general rule (Reilly et al, 1997[4]).

Hazard is a biological chemical or physical agent in, or condition of, food, with the potential to cause harm, whereas, risk is an estimate of the probability and severity of adverse health effects in exposed populations, consequential to hazard(s) in food (Howgate et al, 1995[5]).

Food-borne trematod infections, food borne diseases associated with pathogenic bacteria, and viruses, residues of agro-chemical products veterinary drugs and heavy metal contamination have all been identified as potential hazards of aquaculture product (Garret et al, 1977[6] and Reilly et al, 1997[4]). These hazards are usually associated with the aquaculture habitat, production method, and management techniques (Reilly et al, 1997[4]).

Fortunately, one of the several advantages of aquaculture as a source of food fish is that, the producer can exert control over the intrinsic quality, including the safety, of the products. (Howgate, et al, 1997[5]).

The Objectives of this paper therefore is to:

1. Review the available information of food safety hazards associated with fish culture.

2. Highlight the significance and severity of risk posed by the identified hazards in the culture system.

3. Recommend control and management strategies that will eliminated or reduce the risks associated with fish culture in stagnant ponds/inland water in Niger Delta Area. 


\section{Types Of Hazards And Control Measures}

There are basically two main types of food safety hazards associated with the production of Clarias species, in the mostly stagnant ponds and inland waters in the Niger Delta Area. They are chemical and biological hazards.

\section{A. Chemical Hazards}

Chemical hazards can be present in aquaculture products by exposure to certain compounds used in the aquaculture system itself and by acute and chronic pollution of waterways or sources of water used (Reilly et al, 1997[4] and FAO/NACA/WHO, 1999[7]).

Clarias culture in the inland waters of the Niger Delta Area carries a great risk of contamination from pollutants that are hazardous to human health. One of such pollutants is chlorinated hydrocarbon from crude oil. Frequent oil spillages in the Niger Delta Area are a common sight.

Pollution from oil and gas exploration is a potential hazard of inland fish production (Jamabo \& Ibim, 2006[8]). Unfortunately, little information exists on the level of these pollutants in the cultured fish, to allow risk assessment. Oil and gas exploration affects the fisheries by means of chronic input of hydrocarbons and associated brines that find their way into fish flesh. These chlorinated hydrocarbons are very persistent in the flesh of fish and are potential hazards to man. (Jamabo \& Ibim, 2006[8]; FAO/NACA/WHO, 1999[7]).

Other pollutants of great concern are heavy metals, methyl mercury is hazardous to human health (Howgate et al, 1997[5]). The risk of unsafe levels of metal in fish is very low (FAO/NACA/WHO, 1999[7]).

Clarias culture in inland waters carries a greater risk of contamination from agro-chemicals. Another Chlorinated hydrocarbons of great concern for human health are chlorinated insecticides and their degradation products, polychlorinated benzodioxins and furans. Examples of chlorinated insecticides are Dichlorodipheyltrichlorenthane (DDT) and polychlorinated biphenyls (PCB). Little information exists on their effects on cultured fish and fish products. However, from the available data, aquaculture products contain chlorinated hydrocarbons, though reported values are below the maximum limit permitted in foodstuffs (FAO/NACA/WHO, 1999[7]).

Chemical fertilizers are also agro-chemical that is widely applied to semi intensively managed ponds to stimulate phytoplankton blooms. Such fertilizers are usually inorganic in nature and are usually water soluble. Although some of these compounds may be considered as hazards in their own way, they pose minimal risk to food safety in aquaculture products when used appropriately (Reilly et al, 1997[4]; FAO/NACA/WHO, 1999[7]).

Chemotherapeutants are used to treat fish and the environment in which fish are grown, to control diseases and pests. The chemicals used are selected to have low toxicity to fish and subsequently to humans (Howgate et al, 1997[5]). However, the use of chemotherapeutants has been greatly limited as a result of the use of vaccines, coupled with change in husbandry practices (FAO/NACA/WHO, 1999[7]).

It was reported that, the use of antimicrobial agents in the aquatic environment is a cause for concern, both in terms of potential environmental risk and potential human health implications. There are now reports of antibiotics resistance which are transferred to consumers. The danger is that illness in humans caused by antibiotic-resistant organisms derived from aquatic products, or the environment of aquaculture systems, might not respond to medical treatment (Howgate, 1997[5]). This is of special concern in countries where regulation for the use of antimicrobials is not effectively enforced or do not exist at all (Reilly et al, 1997[4]; FAO/NACA/WHO, 1999[7]). Though limited data exists on the health risks associated with the use if antimicrobials in aquaculture residues in products can be controlled by following the recommended withdrawal times.

\section{B. Biological Hazards}

The principal biological agent that causes hazards in fish foods are bacteria, viruses and parasites.

Parasites related food safety concerns in aquaculture are limited to a few helminthes species. They are the Nematodes, Cestodes and Trematodes (Reilly et al, 1997[4]; FAO/NACA/WHO, 1999[7]). The main human diseases caused by fish borne parasites are trematodiasis, cestodiasis and nematodiasis.

Trematodes are the most important parasites of fish and fish products. These parasites can cause illness ranging from debilitation to cancer and to death. Fishbone trematodiasis is an important disease in various parts of the world. Control of trematodiasis entails proper cooking of fish; and maintain some proper sanitary condition in aquaculture systems.

It was reported that, there are two broad groups of bacteria of public health significance that will contaminate products of aquaculture: those naturally present in the environment - indigenous microflora (e.g. Aeromonas species, Clostribuim botulinum, Vibrio parahaemolyticus, Vibrio cholerea and Listeria species), and those introduced into the environment by contamination via, domestic animal excreta and/or human waste, nonindigenous microflora (e.g. Enterobacteriacae such as Salmonella species and Escherichia coli (Huss, 1994[9]). 
High stocking densities and high feed inputs in Clarias culture results in deterioration of the pond environment and diseases. Data on farmed fish pathology and microbiology suggest a potential prevalence of Vibrio species, and Aeromonas species (Gluffrida, 2003[10]).

There is a rapid die-off of enteric organisms in well managed aquaculture system (Edwards, 1992[3]). However, significant numbers remain on the skin and in guts of fish and can pose health risk to consumers. Adequate coking before consumption will eliminate this risk. Raw or improperly cooked fish food especially Clarias can lead to high health risk of consumers (FAO/NACA/WHO, 1999[7]).

\section{Strategies For Food Safety Assrance}

Food-borne diseases associated with fishery products of Clarias and other species can be largely prevented and controlled through appropriate food-safety measures. Responsibility for food safety hazard associated with products from aquaculture is shared between governments, the fish-farming and processing industries, and consumers. For its part, the aquaculture sector should institute farm management programmes, where appropriate, based on the principles of the HACCP system. It has been recognized that such measures are impractical in small-scale subsistence aquaculture, where attention should instead be focused on food safety education (FAO/NACA/WHO, 1999[7]).

The HACCP system can be applied at any stage, from production to consumption of food. It permits a systematic approach to the identification and assessment of hazards and risks associated with the production, distribution and use of aquatic foods, and puts the responsibility for the aquaculture of safe products on the aquaculture sector. The principles of HACCP system should form an integral part of the from-to-table food safety continuum, thereby increasing consumer confidence in products from aquaculture and expanding market opportunities. There is an international movement towards the adoption of the HACCP system in the seafood sector, with such major markets as the European Union and North America introducing mandatory requirement for HACCP implementation. International bodies, such as Codex Alimentarius Commission, are advocating a harmonized approach for the introduction of the HACCP system in the food sector, and the Codex Fish and Fishery Products to include the principles of HACCP.

\section{Conclusion}

Clarias culture is of great importance in the Niger Delta Area. Therefore, there is need for the agricultural sector to increase research on the food safety hazards associated with the fish and fish products produced in this area, in order to determine the level of the effects of the different biological and chemical hazards. The increase in research efforts will also provide enough data for the application of risk assessment techniques, and the implementation of management and control strategies and eventually, consumption of safe Clarias in the Niger Delta Area.

\section{Books:}

\section{References}

[1] F. E. Ahmed(ed), Seafood Safety committee on the Evaluation of the safety of fishery products. Food and Nutritional Board, Institute of Medicine, Washington, National Academy Press, 1991a, 474p.

[2] F. E. Ahmed, Symposium on Issues in Seafood Safety. Institute of Medicine Washington, National Academy Press. I991b,239pp.

\section{Proceeding Papers:}

[3] P. Edwards, Reuse of human wastes in aquaculture. UNDP - World-bank water and Sanitation Program. Washington. World Bank, 1992, 350pp.

[4] A. C. Reilly, Food Safety and Products from Aquaculture FAO Fisheries Circular Rome FAO. Lima dos Santos \& M. Philips, 1997

[5] P. Howgate, Review of the hazards and quality of products from aquaculture. Paper presented at the meeting of the Joint FAO/NACA/WHO study group on food Safety Associated with products from Aquaculture, Bangkok, Thailand, 22-26 July 1997.

[6] E. S.Garret, M. L. Jahneke, and C.A.M Lima dos Santos, Public and animal health implications of aquaculture. Paper presented at the international Life Science Institute conference on Emerging Foodborne Pathogens: Implications and Control, Alexandria, Va, U.S.A., March 1997.

[7] FAO/NACA/WHO study group, Food Safety Associated with Products from Aquaculture. Technical report series (Full paper) No 883. ISBN: 1999, 922120883.

[8] N. A. Jamabo, and A. T. Ibim, Impact of the Effect of Oil Pollution on the Coastal Fisheries of Rivers State, Nigeria. Paper Presented at the International Conference for infrastructure and Environmental Development, Abuja, 2006.

[9] H.H. Huss, Assurance of Seafood Quality. FAO Fisheries Tech. Paper No 334, Rome FAO.1994, 169pp.

[10] A. Giuffrida, Application of risk management to the production chain of intensively reared fish. Vet. Res. Comm. 27, 2003, 491496. 